\author{
FINAL REPORT \\ U.S. Department of Energy
}

\title{
EVALUATION OF ISOTOPIC DIAGNOSTICS FOR SUBSURFACE CHARACTERIZATION AND MONITORING: FIELD EXPERIMENTS AT THE TAN AND RWMC (SDA) SITES, INEEL
}

\author{
Principle Investigator: Donald J. DePaolo \\ Institution: E.O. Lawrence Berkeley National Laboratory \\ Collaborators: Mark E. Conrad and B. Mack Kennedy \\ Institution: E.O. Lawrence Berkeley National Laboratory \\ Eric C. Miller, Erick R. Neher and Thomas R. Wood \\ Institution: Idaho National Engineering and Environmental Laboratory \\ P. Evan Dresel and John Evans \\ Institution: Pacific Northwest National Laboratory
}

Project Number: 55351

Grant Number:

Grant Project Officers:

Project Duration: September 1, 1996 to September 30, 1999 


\section{Table of Contents}

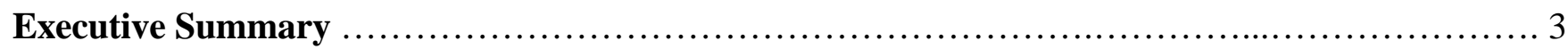

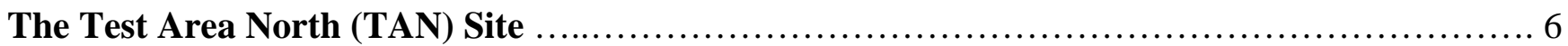

The Radioactive Waste Management Complex (RWMC) …............................... 17

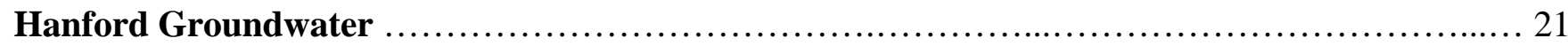

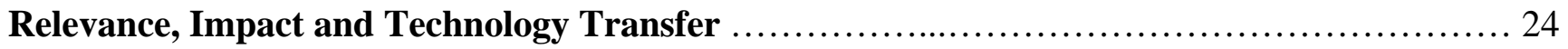

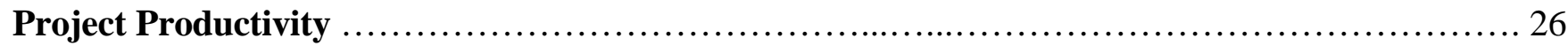

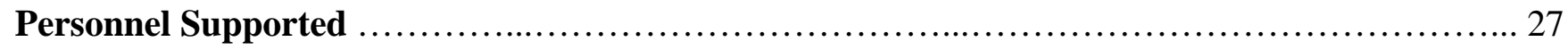

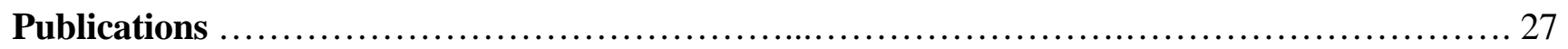

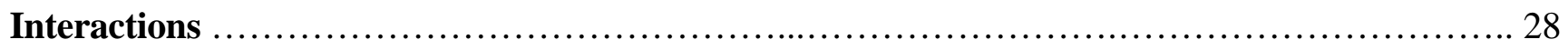

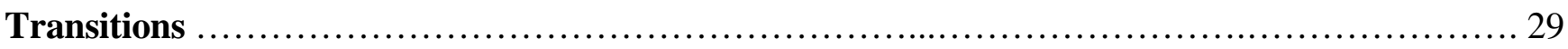

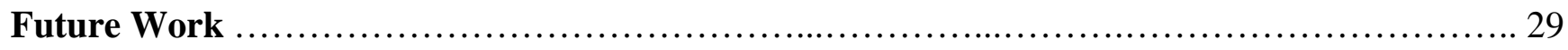

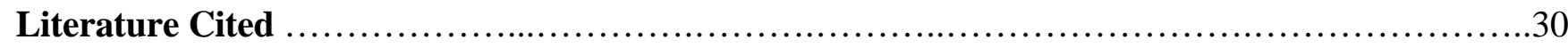

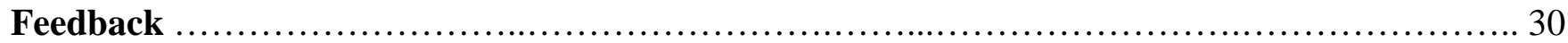

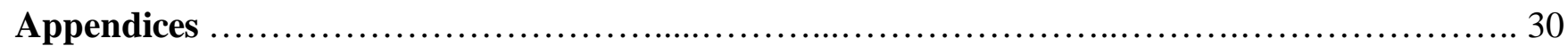

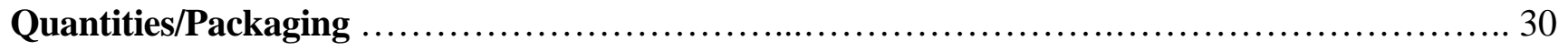




\section{Executive Summary}

The purpose of this project was to explore and refine applications of isotope measurements for guiding environmental remediation strategies. The isotopic compositions of samples from field sites were analyzed to address both basic scientific issues and site-specific problems. Initial efforts were concentrated on two sites at the Idaho National Engineering and Environmental Laboratory (INEEL). During the final year of the project, the focus of work was shifted to the Hanford site in Washington. The Test Area North (TAN) site at INEEL consists of a $2 \mathrm{~km}$-long plume of mixed wastes containing low-level radionuclides, sewage and chlorinated solvents that were injected into the groundwater between 1955 and 1972. Isotopic measurements of groundwater samples were made to address questions about the source of the groundwater and the regional hydrology at TAN. These data show that there is a significant input to the groundwater from playa lakes that were located west of the TAN site prior to the 1950s (since that time, inflow to the playas has been diverted for agricultural uses). Radiocarbon dates of the playa waters indicate a mean infiltration rate of 3-5 cm/year. These results explain the groundwater flow patterns observed in the plume and provide constraints on transport rates.

Another goal of the work at the TAN site was to evaluate levels of degradation of the contaminants in the plume. Mixing of the playa water with regional groundwater produced a range of strontium isotopic compositions in the plume that can be used to estimate the degree of dilution of the injected wastewater. The concentrations of trichloroethene (TCE), the primary contaminant in the plume, drop off faster than the strontium isotope ratios, indicating that natural degradation of TCE is occurring at the site. This is supported by decreases in the carbon isotope ratio of dissolved inorganic 
carbon compounds (DIC) in the plume. Organic compounds, such as TCE and sewage, have low carbon isotope ratios that will be reflected in the carbon isotope ratios of DIC produced as a byproduct of biodegradation. During FY99, the work on the TAN plume was expanded to help monitor an experiment designed to enhance biodegradation of the chlorinated solvents in the vicinity of the injection well. In addition to tracking changes in the carbon isotope ratios of the groundwater DIC, the carbon isotopic compositions of the contaminants and potential biodegradation byproducts were also analyzed. These data confirmed that complete biologic dechlorination of the TCE was being stimulated by the nutrients injected into the disposal well.

Samples from the Radioactive Waste Management Complex (RWMC) at the INEEL were analyzed to determine the extent of natural degradation of contaminants in the unsaturated zone at the site. Besides the radionuclides, the waste drums at the RWMC contained significant amounts of organic contaminants including chlorinated solvents and lubricating oils. Leaks in the drums led to a plume of vapor-phase contaminants in the unsaturated zone. Over a two-year period, the concentrations and isotope ratios of $\mathrm{CO}_{2}$ in gas samples from monitoring wells at the site were measured. The concentrations of $\mathrm{CO}_{2}$ in shallow gas samples $(10-25 \mathrm{~m})$ from the vicinity of the disposal pits were significantly elevated relative to the levels of $\mathrm{CO}_{2}$ in background wells. Further, the carbon isotope ratios of $\mathrm{CO}_{2}$ from the contaminated area were lower than carbon isotope ratios of $\mathrm{CO}_{2}$ from the background wells, suggesting that the increased levels of $\mathrm{CO}_{2}$ were derived from the organic contaminants. In addition, the radiocarbon content of the high- $\mathrm{CO}_{2}$ samples was very low; indicating that they were produced from chemicals derived from fossil fuels (e.g., solvents, lubricating oils). 
In the final year of the project, research on the isotopic signatures of groundwater at the Hanford site in Washington was begun. Production of fuel for nuclear weapons during the cold war period, resulted in the release of significant amounts of radionuclides to the environment at Hanford. The goal of our work was to use natural isotopic tracers to identify pathways and mechanisms of wastewater infiltration through the vadose zone to groundwater. Preliminary results indicate that the strontium isotope ratio of the groundwater is a very effective indicator of the proportion of process water in the groundwater. Further, other isotopic measurements are indicative of processes such as evaporation, degradation of organic matter and interaction with carbonate minerals. All of these isotopic signals hold great promise for identifying specific waste streams and tracking their infiltration to groundwater.

The results of these studies clearly demonstrate how isotopic measurements can be used to help answer questions of critical importance for environmental management. Our primary findings are:

1. Natural biodegradation of chlorinated solvents can be documented by carbon isotope ratios.

2. Engineered biodegradation can be verified by measurements of natural isotopic tracers.

\section{Natural isotopic tracers can be used in lieu of injection experiments for characterization of} groundwater systems.

Further, these studies have produced important field data about basic scientific processes such as the infiltration of water through the unsaturated zone and the potential for subsurface biologic activity in arid environments. At both the INEEL and Hanford, the scientific collaborations that have been developed between the researchers from the Berkeley Lab and the investigators from the sites have led to proposals of additional studies using the principles developed through this project. 


\section{The Test Area North (TAN) Site}

\section{Research Objectives}

The Test Area North (TAN) site at the Idaho National Engineering and Environmental Laboratory is located on the northern edge of the Snake River Plain in eastern Idaho. The geology at the TAN site is similar to the geology at the RWMC; consisting of basalt flows separated by sedimentary interbeds. The depth to groundwater at the site is about $65 \mathrm{~m}$. At 120 to $160 \mathrm{~m}$ depth (increasing towards the south), a relatively continuous, impermeable interbed (the "Q-R Interbed") separates the upper part of the aquifer from the main aquifer.

Between 1955 and 1972, a wide variety of waste materials, including low-level radioactive isotopes, sewage and chlorinated solvents, were injected into the upper, unconfined aquifer through a 95 $\mathrm{m}$ deep well (TSF-05). The result of this activity is a $2 \mathrm{~km}$ plume that is currently expanding at a rate of approximately $100 \mathrm{~m}$ per year. So far, the plume is limited to the upper, unconfined aquifer at the site.

The primary contaminant of concern at the TAN site is trichloroethene (TCE). The regulatory goals for the site are to eliminate the source of contamination, defined as the $5000 \mu \mathrm{g} /$ liter concentration isograd for TCE, and to decrease the remaining contamination to below $5 \mu \mathrm{g} /$ liter. During the first two years of this project, the primary remediation technique utilized at the site was pump-and-treat. However, because of the low solubility of TCE, the rate of removal was slow and an enhanced bioremediation system was tested at the site (see below) during FY99.

Our research at the TAN site had three primary objectives. These were:

1. Determine the primary factors affecting regional groundwater flow at the TAN site - The primary direction of groundwater flow in the Snake River Aquifer is from the northwest to the southeast. At the TAN site, however, groundwater flow (as defined by the shape of the contaminant plume) is roughly perpendicular to the regional flow direction. We conducted a regional study using natural isotopic tracers to define the potential sources of groundwater in the TAN area and determine their influence on groundwater flow patterns.

2. Evaluate the potential for natural degradation of TCE in the TAN plume - The potential for natural degradation of the contaminants in the plume is an important factor for assessing the need for remedial action in the downstream areas of the plume. By comparing changes in the isotopic signatures of groundwater in the plume to the concentrations of TCE, we can differentiate degradation of the contaminants from simple dilution.

3. Monitor enhanced bioremediation experiment - During FY99, a field-scale pilot study was conducted to examine the possibility of enhancing bioremediation of TCE in the vicinity of the injection well, TSF-05. By monitoring the carbon isotope ratios of TCE and the intermediary products of biological degradation of TCE, we can confirm that complete biodegradation of TCE is occurring and estimate the extent of degradation.

Approach. There are a variety of natural isotopic tracers available for use in hydrologic studies. For this project, we concentrated on measurements of the stable hydrogen $(\delta \mathrm{D})$ and oxygen $\left(\delta^{18} \mathrm{O}\right)$ isotope compositions of the waters, the stable carbon $\left(\delta^{13} \mathrm{C}\right)$ and radiocarbon $\left({ }^{14} \mathrm{C}\right)$ isotope compositions of dissolved inorganic carbon compounds (DIC) in the groundwater, the ${ }^{87} \mathrm{Sr} /{ }^{86} \mathrm{Sr}$ ratios of dissolved strontium in the water and the $\delta^{13} \mathrm{C}$ values of chlorinated solvents in the TAN plume.

Hydrogen and oxygen isotope measurements of water - Craig (1961) found that the $\delta \mathrm{D}$ and $\delta^{18} \mathrm{O}$ isotope ratios of most rainwater lie on or near a line of slope eight on a plot of $\delta \mathrm{D}$ versus $\delta^{18} \mathrm{O}$ (commonly called Global Meteoric Water Line or GMWL). Where rainwater from a specific area falls 
on the GMWL is a function of a variety of factors, including the distance of the area from the ocean, the altitude and the temperature.

Further, when surface waters undergo evaporation before they infiltrate into the subsurface, the hydrogen and oxygen isotope ratios of the waters will be altered. As the water evaporates, the lighter isotopes are preferentially separated into the vapor phase and the residual water becomes enriched in D and ${ }^{18} \mathrm{O}$. Depending on the humidity and temperature of an area, evaporation trends will generally have slopes of between three and six on plots of $\delta \mathrm{D}$ versus $\delta^{18} \mathrm{O}$. This will cause highly evaporated waters to lie significantly off of the GMWL.

Carbon isotope measurements of groundwater DIC - The $\delta^{13} \mathrm{C}$ and ${ }^{14} \mathrm{C}$ values of dissolved inorganic carbon compounds (DIC) in the groundwater can be influenced by a variety of factors. Surface waters are generally close to equilibrium with atmospheric $\mathrm{CO}_{2}\left(\delta^{13} \mathrm{C}\right.$ between 0 to $-2 \%$ and ${ }^{14} \mathrm{C}$ $\sim 110 \%$ of modern), although biodegradation of organic matter tends to shift the $\delta^{13} \mathrm{C}$ values to more negative numbers. When the water infiltrates through the soil horizon, it equilibrates with soil gas $\mathrm{CO}_{2}$ derived from processes such as root respiration and degradation of organic matter, causing the $\delta^{13} \mathrm{C}$ values of the DIC to become more negative. As the water moves through the vadose zone, it can also interact with subsurface carbonates. Depending on the conditions, the DIC can be shifted towards isotopic equilibrium with the carbonates. Finally, the carbon isotope compositions of the $\mathrm{DIC} / \mathrm{CO}_{2}$ can also be affected by biodegradation of contaminants (as discussed in the section on the RWMC).

Measurements of the ${ }^{87} \mathrm{Sr}{ }^{86} \mathrm{Sr}$ ratios of dissolved strontium - The strontium isotope ratio of groundwater is a very sensitive tracer of its source terrain. Due to the low concentration of strontium in rainwater, the water assumes the ${ }^{87} \mathrm{Sr} /{ }^{86} \mathrm{Sr}$ ratio of the soils. The ${ }^{87} \mathrm{Sr} /{ }^{86} \mathrm{Sr}$ ratios can also be shifted by interaction with the rock matrix in the aquifer. The concentrations of strontium in water are typically 1000 times less than the concentrations in the rock. After relatively minor degrees of interaction with the matrix, the ${ }^{87} \mathrm{Sr} /{ }^{86} \mathrm{Sr}$ ratios of the water will quickly become dominated by the ${ }^{87} \mathrm{Sr} /{ }^{86} \mathrm{Sr}$ ratios of the rock. The length-scale of this change can be used to calculate factors such as the flow velocity of the fluids and/or the relative amounts of water and rock in the system (Johnson and DePaolo, 1997a,b).

$\delta^{13} \mathrm{C}$ analyses of chlorinated solvents - Under anaerobic conditions, bacteria can degrade chlorinated solvents by sequentially removing the chlorine atoms from the molecules (see Figure 1). This process is less effective as the compounds become less chlorinated. In addition, the less chlorinated compounds are also more volatile. As a result, it is often difficult to determine whether or not complete dechlorination of TCE to ethene is occurring.

A recent study (Hunkeler et. al, 1999) found that the reductive dehalogenation of chlorinated solvents results in large shifts in the stable carbon isotopic ratios of the compounds. In essence, the bacteria preferentially break the ${ }^{12} \mathrm{C}-\mathrm{Cl}$ bonds over the ${ }^{13} \mathrm{C}-\mathrm{Cl}$ bonds. This causes the products to have significantly lower $\delta^{13} \mathrm{C}$ values than the substrate. In addition, as the substrate is consumed, the residual becomes enriched in ${ }^{13} \mathrm{C}$. The amount of enrichment is a function of the degree of dechlorination that has occurred. Therefore, it is possible to use shifts in the carbon isotope ratios to track the efficacy and extent of bioremediation of the chlorinated solvents.

\section{Methods and Results}

Water samples for isotopic analyses were collected from potential source areas and monitoring wells. Samples for $\delta \mathrm{D}$ and $\delta^{18} \mathrm{O}$ of water and $\delta^{13} \mathrm{C}$ and ${ }^{14} \mathrm{C}$ of DIC were collected in headspace-free bottles that were kept at $\sim 4^{\circ} \mathrm{C}$ until the DIC could be extracted from the samples (within 2 weeks of sampling). For ${ }^{87} \mathrm{Sr} /{ }^{86} \mathrm{Sr}$ analyses, a separate sample was collected in a separate sample bottle and acidified with nitric acid.

For hydrogen isotope analyses, the 


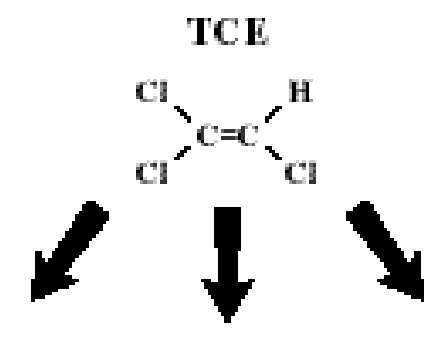

Figure 1. Reductive dechlorination pathway used by bacteria to degrade TCE. Although some 1,1-DCE and trans-1,2-DCE can be formed, cis-1,2-DCE is the predominant dichloroethene isomer produced from TCE.

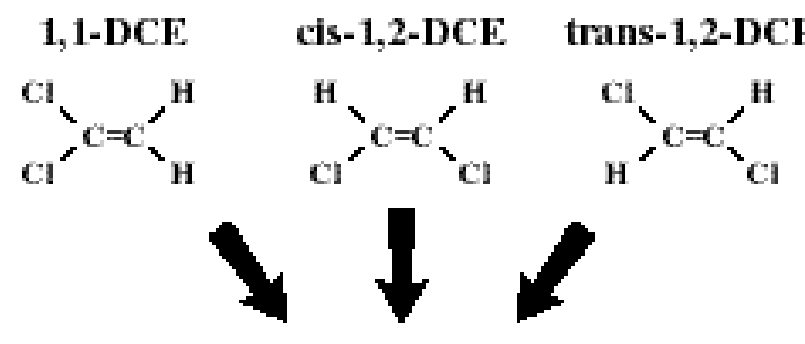

vinyl chloride

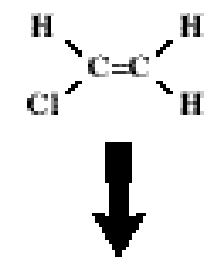<smiles>C=C</smiles>

waters were converted to hydrogen gas by reduction with zinc metal and then analyzed using the VG Prism at the Center for Isotope Geochemistry at LBNL. The $1 \sigma$ variation for multiple analyses of waters is $2 \%$. Oxygen isotope analyses were done using the Isoprep 18 automated system interfaced with the Prism. This system equilibrates $\mathrm{CO}_{2}$ gas with water samples at $25^{\circ} \mathrm{C}$ and then expands the $\mathrm{CO}_{2}$ into the Prism for analysis. The $1 \sigma$ reproducibility for the $\delta^{18} \mathrm{O}$ values using this system is $0.1 \%$.

The carbon isotopic compositions of the DIC were analyzed following the techniques outlined in Conrad (1997). DIC was extracted from the water samples by acidifying the water with phosphoric acid. The $\delta^{13} \mathrm{C}$ value of the resulting $\mathrm{CO}_{2}$ was then analyzed on the Prism. Duplicate analyses were generally within $\pm 0.2 \%$ o. For ${ }^{14} \mathrm{C}$ analyses, an aliquot of the $\mathrm{CO}_{2}$ was reduced to graphite and analyzed at the Center for Accelerator Mass Spectrometry at Lawrence Livermore National Laboratory. The precision of these analyses is generally better than $1 \%$ of modern carbon.

The ${ }^{87} \mathrm{Sr}{ }^{86} \mathrm{Sr}$ ratios of the dissolved strontium were analyzed isotope analyses were measured by isotope dilution using thermal ionization mass spectrometry at CIG. These analyses are accurate to approximately \pm 0.000002 .

Analyses of the $\delta^{13} \mathrm{C}$ values of the chlorinated solvents were done by purging the compounds from the groundwater samples using helium. They were then cryogenically trapped and injected into a GC-combustion system where the different compounds were separated and combusted to form $\mathrm{CO}_{2}$. The $\delta^{13} \mathrm{C}$ values of the individual compounds were then analyzed in continuous-flow mode using the Micromass Isoprime mass spectrometer at CIG. The reproducibility of duplicate measurements was generally better than $\pm 0.5 \%$ o. 
Regional groundwater flow patterns. Groundwater flow in the TAN area does not follow the general pattern in the Snake River Aquifer (northwest to southeast). In the vicinity of the injection well, TSF05, flow is to the southeast. Downstream, in the distal regions of the contaminant plume, groundwater flow shifts to the south. There are several factors that could lead to the distinctive groundwater flow field in the TAN area. Significant amounts of process water used at the site were dumped into an evaporation pond located directly to the northwest of the injection well. Infiltration of this water resulted in a groundwater mound beneath the pond that could influence groundwater flow. In addition, prior to development of the site, there was a playa lake located to the west of the TAN site. During the early twentieth century, much of the water in the Big Lost River (the source of inflow to the playa) was diverted for agricultural purposes. When the site was developed in the 1950s, engineered barriers were emplaced to ensure that the playa would not fill. However, infiltration of the water from the playa could still be affecting the regional groundwater flow patterns in the upper, unconfined aquifer at the TAN site. It is also possible that differences in the permeability of the rock caused by precipitation of secondary minerals beneath the playa are affecting flow.

Determining the importance of these factors is critical for the long-term remediation plan for the site. If it is a transitory effect caused by infiltration of the process waters, then potential changes in the shape and direction of the plume need to be taken into account, especially if any downstream barriers or treatment systems are deemed necessary to control the plume. To address these questions, we analyzed the isotopic compositions of water samples from the potential sources of the groundwater, from monitoring wells in the TAN area and regional wells.

Results and Discussion - The $\delta^{18} \mathrm{O}$ values of water samples from the upper, unconfined aquifer at TAN are plotted on a map of the TAN area in Figure 2. Also shown on Figure 5 are the TCE contours for the plume at the time the samples were collected and the locations of the injection well (TSF-05) and the evaporation pond. These $\delta^{18} \mathrm{O}$ values of the samples have a relatively large range of values $(-15.3 \%$ to $-18.5 \%$ o $)$ that generally decrease from west to east, but do not directly correlate with distance from the 


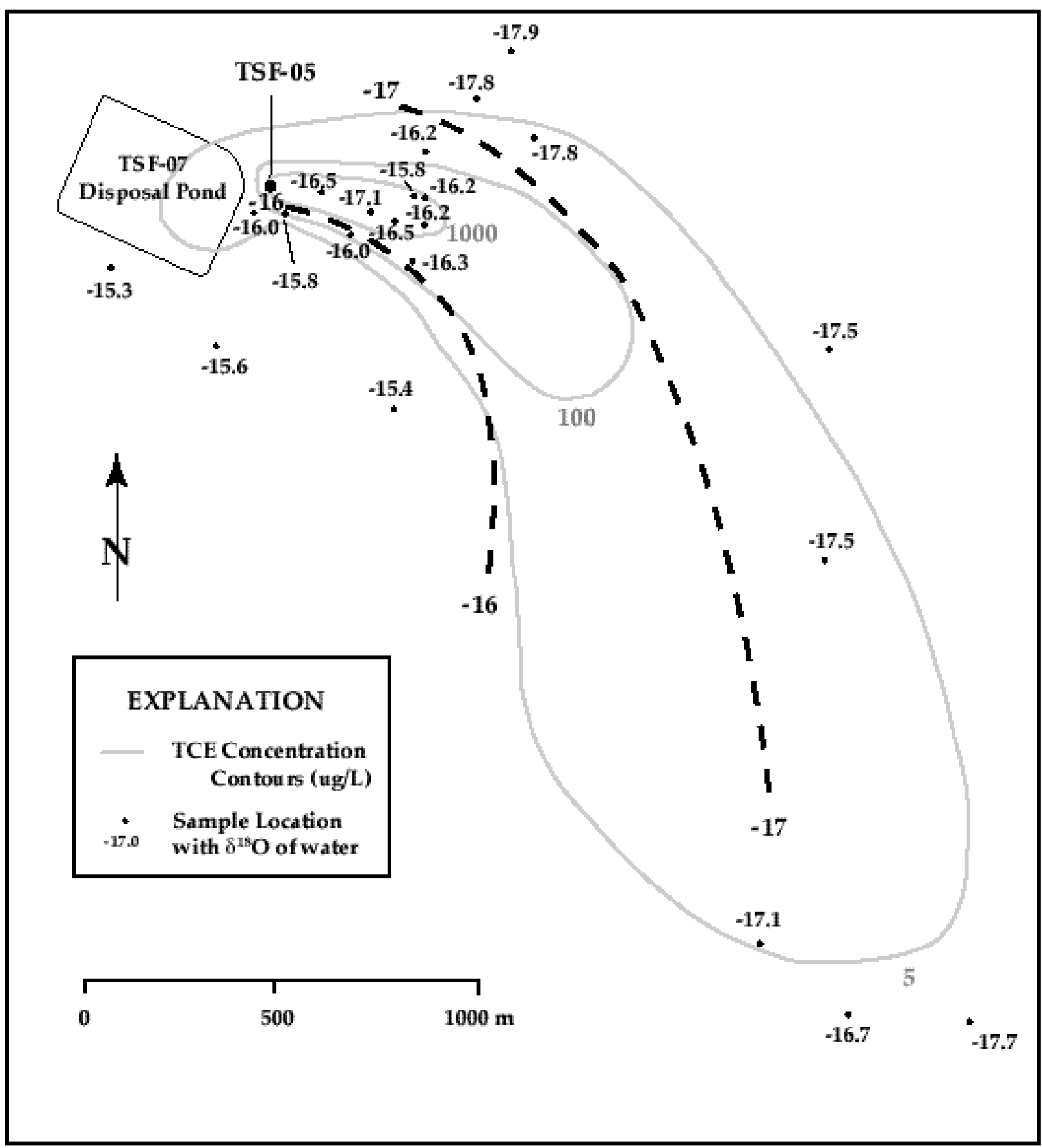

Figure 2. Map of the TAN area with average $\delta^{18} \mathrm{O}$ values measured for groundwater samples from the upper, unconfined aquifer. Also shown are the concentration contours for TCE and the locations of TSF-05, the injection well, and the TSF-07 Disposal Pond. 
evaporation pond or injection well. The oxygen isotope compositions of all of the samples analyzed are plotted versus their hydrogen isotope compositions on Figure 3. The data form a classical evaporation trend with a slope of approximately 5 that intersects the GMWL at a $\delta^{18} \mathrm{O}$ value of between -18 and $-19 \%$ o.

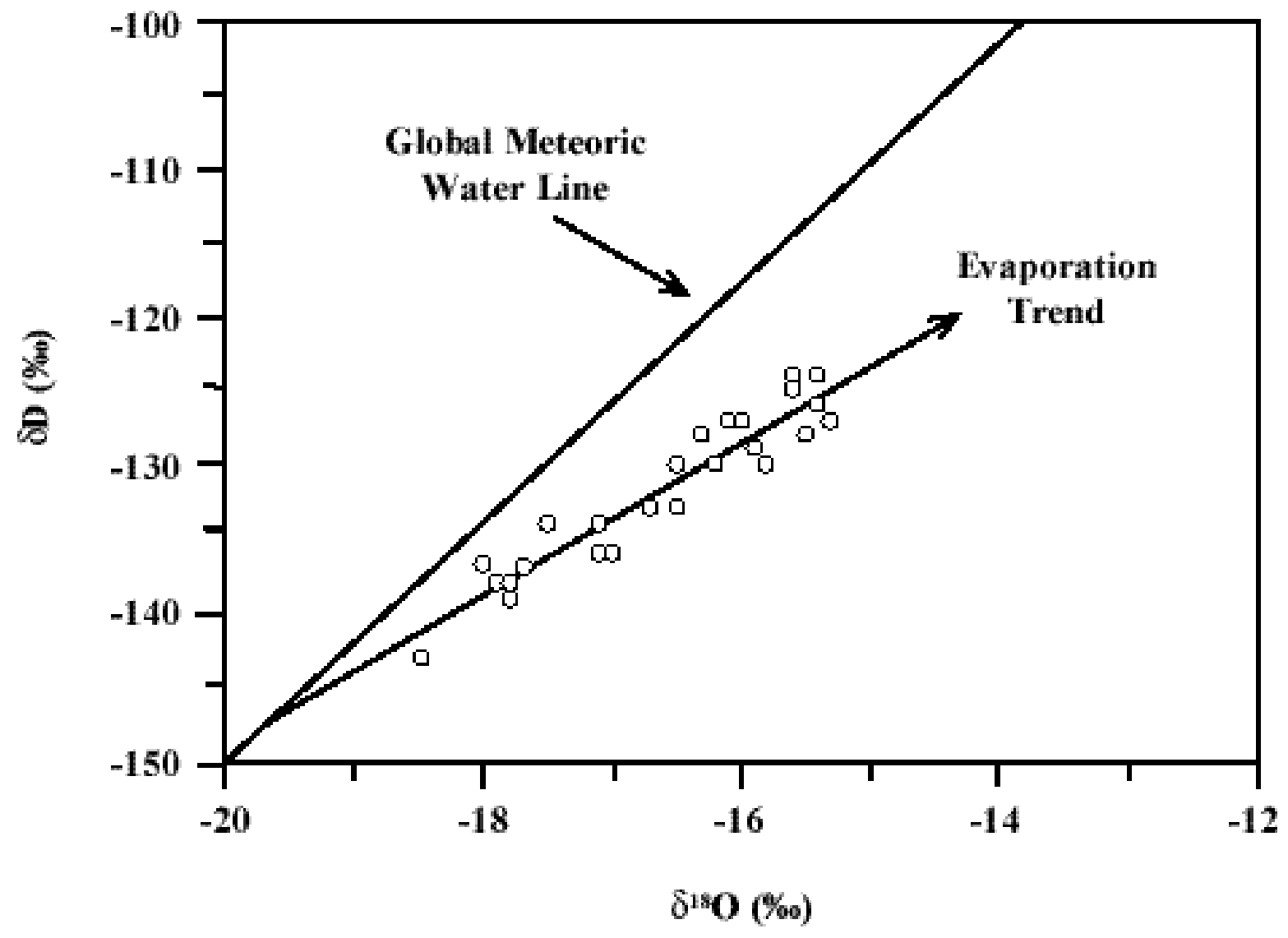

Figure $3-\delta^{18} \mathrm{O}$ and $\delta \mathrm{D}$ data for water samples collected from monitoring wells at the TAN site. Also shown are the GMWL and a best fit line through the data (which is equivalent to a typical trend of data observed for evaporated waters).

It would clearly take a significant amount of evaporated water to have this large of an effect on the isotopic composition of the groundwater. The extent of the area with $\delta^{18} \mathrm{O}$ values of less than $-17 \%$ o is approximately $2 \mathrm{~km}^{2}$. The average thickness of the upper, unconfined aquifer in this area is about 75 $\mathrm{m}$. Assuming an average water-filled porosity of $10 \%$, then there is about $1.5 \times 10^{10}$ liters of water in this volume. For an average $\delta^{18} \mathrm{O}$ of $-16 \%$ within this volume, approximately $5 \times 10^{9}$ liters of evaporated water with an average $\delta^{18} \mathrm{O}$ value of $-12 \%$ o (representing a loss of $\sim 50 \%$ of the volume of the water to evaporation) would have to have been added to the aquifer to produce the observed pattern. Around $5 \times 10^{7}$ liters of water is estimated to have been dumped into the evaporation pond and a much smaller volume was pumped into the disposal well. Even if this estimate is low by an order of magnitude, there is no way that this water could have produced the strong evaporated signal in the groundwater at the site. The playa lake that existed to the west of the site is the only possible source of such a significant volume of evaporated water. Figure 4 is a map of the playa lake with the TAN plume and the $\delta^{18} \mathrm{O}$ values of samples collected from the area. Given the location and size of the playa, infiltration of water from the 
playa could be the cause of the flow patterns in the TAN plume. This is somewhat surprising since there has been no water in the playa for over 50 years.

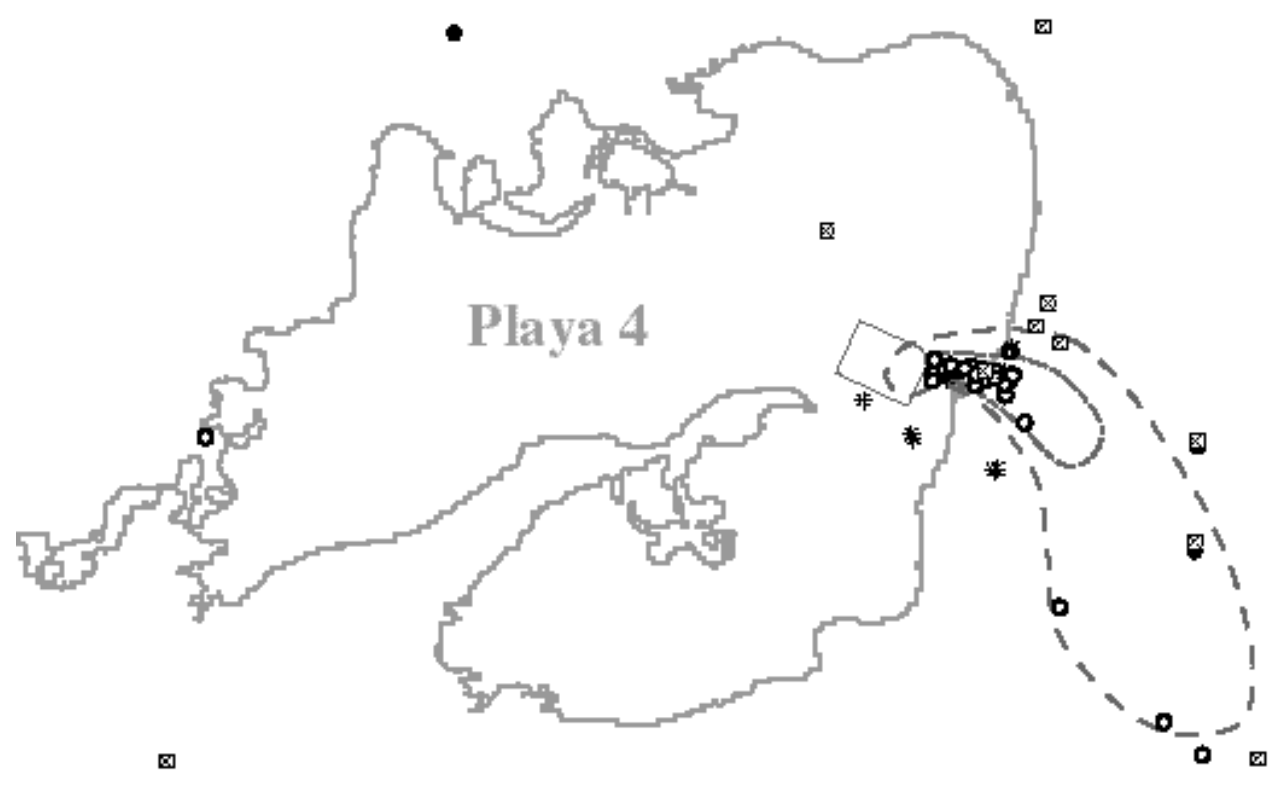

- $\delta^{18} \mathrm{O}<-18 \%$

四 $\delta^{18} \mathrm{O}=-17.0$ to $-17.9 \%$

o $\delta^{18} \mathrm{O}=-16.0$ to $-16.9 \%$

* $\delta^{18} \mathrm{O}>-16 \%$

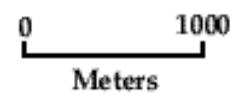

Figure 4. Map with the location of the TAN plume relative to the location of the playa that existed in the area adjacent to the TAN site (Playa 4). Also shown are the $\delta^{18} \mathrm{O}$ values of groundwater samples in and around the area. Samples with values greater than $-17 \%$ o have undergone significant evaporation.

The strontium isotope data for the groundwater samples provide additional evidence that the water in the TAN plume is derived from mixing of water from the playa with regional groundwater. The isotopic compositions of the potential sources for the groundwater are listed in Table 1. There are differences in the $\delta \mathrm{D}$ and $\delta^{18} \mathrm{O}$ values of the different sources, but the ${ }^{87} \mathrm{Sr} /{ }^{86} \mathrm{Sr}$ ratios of the potential are distinctive. Water from the Birch Creek drainage (and Little Lost River) has relatively high ${ }^{87} \mathrm{Sr} /{ }^{86} \mathrm{Sr}$ ratios of around 0.7120. $\mathrm{The}^{87} \mathrm{Sr} /{ }^{86} \mathrm{Sr}$ ratio of Big Lost River water, which fed the playa, is 0.7104 . The ${ }^{87} \mathrm{Sr} /{ }^{86} \mathrm{Sr}$ ratios regional groundwater in the Snake River aquifer is $<0.710$. The water in the TAN plume ranges between 0.7102 and 0.7105 . The Birch Creek water appears to be confined to the aquifer beneath impermeable layer at the base of the upper, unconfined aquifer. The ${ }^{87} \mathrm{Sr} /{ }^{86} \mathrm{Sr}$ ratio of a sample collected from TAN-18, which is completed below the impermeable layer, is 0.7119 .

Table 1. Average isotopic compositions of potential sources of groundwater at the TAN site. The Snake River Aquifer values are based on the isotopic compositions of samples collected from the Stoddart and Mud Lake Production wells located to the east of TAN.

$\delta \mathrm{D}(\% \circ) \quad \delta^{18} \mathrm{O}(\% \circ) \quad \delta^{13} \mathrm{C}_{\mathrm{DIC}}(\% \circ) \quad{ }^{87} \mathrm{Sr} /{ }^{86} \mathrm{Sr}$




\begin{tabular}{lllll} 
Birch Creek & -145 & -18.7 & -7.0 & 0.7121 \\
Big Lost River & -135 & -17.4 & -1.7 & 0.7104 \\
Snake River Aquifer & -137 & -18.0 & -10.9 & 0.7091 \\
\hline
\end{tabular}

In addition to stable isotope analyses, the radiocarbon ages of DIC in several of the samples from in and around the plume were measured. Within the plume several of the samples were elevated above modern levels, indicating that some of the injected wastes included radiocarbon. Outside of the plume, however, three samples had dates ranging from 1800 to 2800 years bp. Assuming this represents the age of the playa waters, this gives mean infiltration rates of $3-5 \mathrm{~cm} / \mathrm{yr}$. This implies relatively slow infiltration rates for surface waters and suggests that the playa water will continue to affect groundwater flow for a long time into the future.

Evidence for natural attenuation of TCE in the plume. The rate of growth of the TCE plume at the TAN site is less than predicted based upon hydrologic models of groundwater flow. There are also several processes that could be retarding the spread of TCE, including sorption on sediments, volatilization and natural biodegradation. If these processes are occurring, they will have significant implications for management of the plume. One of the primary goals of this project was to use natural isotopic tracers to assess the nature and extent of natural attenuation that is occurring in the plume.

Results and Discussion - The in the TAN plume vary from $\sim 0.7104$ near the injection well to $\sim 0.7102$ at the distal end of the plume. Figure 5 is a plot of the concentrations of TCE in samples from the plume versus their ${ }^{87} \mathrm{Sr} /{ }^{86} \mathrm{Sr}$ ratios. The TCE concentrations decrease much more quickly than the strontium isotope ratios, suggesting that some degree of degradation is occurring in the plume. This data does not distinguish between different types of natural attenuation (e.g., biodegradation, volatilization, sorption).

There is independent evidence that biodegradation of organic matter is occurring in the TAN plume. The $\delta^{13} \mathrm{C}$ values of organic matter tend to be lower than most other sources of subsurface carbon. Figure 6 is a longitudinal cross section of the TAN plume. There is a small, but significant decrease in the $\delta^{13} \mathrm{C}$ values of the DIC in the plume, suggesting that biodegradation of organic matter is occurring. However, in addition to TCE, untreated sewage was also injected into TSF-05. This could also produce the observed shift in the $\delta^{13} \mathrm{C}$ values of the DIC. With only the carbon isotope data, it is not possible to distinguish whether the source of the low- $\delta^{13} \mathrm{C}$ DIC is the TCE and/or the sewage. 


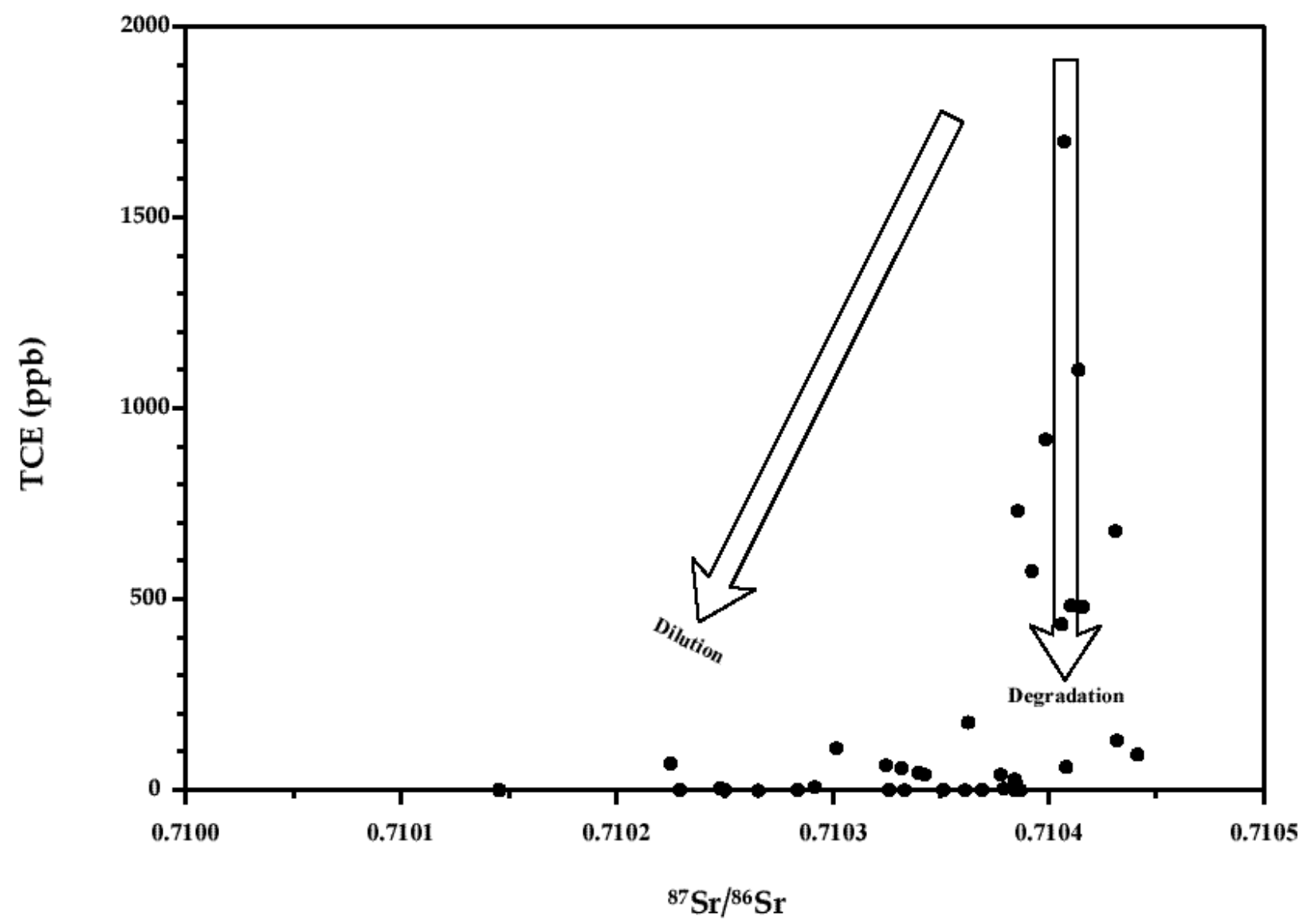

Figure 5. Plot of TCE concentrations versus ${ }^{87} \mathrm{Sr} /{ }^{86} \mathrm{Sr}$ ratio of groundwater samples from the TAN site.

Monitoring of Enhanced In-Situ Bioremediation of TCE. During the final year of this project (FY99), a field-scale pilot study was conducted to evaluate the potential for enhanced, in situ bioremediation of TCE in the source area of the TAN plume. Lactate was injected into TSF-05 to stimulate anaerobic reductive dechlorination of the TCE. As part of an extensive monitoring program for the study, the $\delta^{13} \mathrm{C}$ compositions of TCE and the intermediary byproducts of reductive dechlorination were analyzed for samples taken monthly throughout the test period (about 1 year).

Results and Discussion - The concentrations and carbon isotope ratios of samples collected from TAN 26 are plotted versus time in Figure 7. TAN 26 is located approximately $5 \mathrm{~m}$ from TSF-05 and extendsto the bottom of the aquifer. After an initial increase in the TCE concentration (presumably 


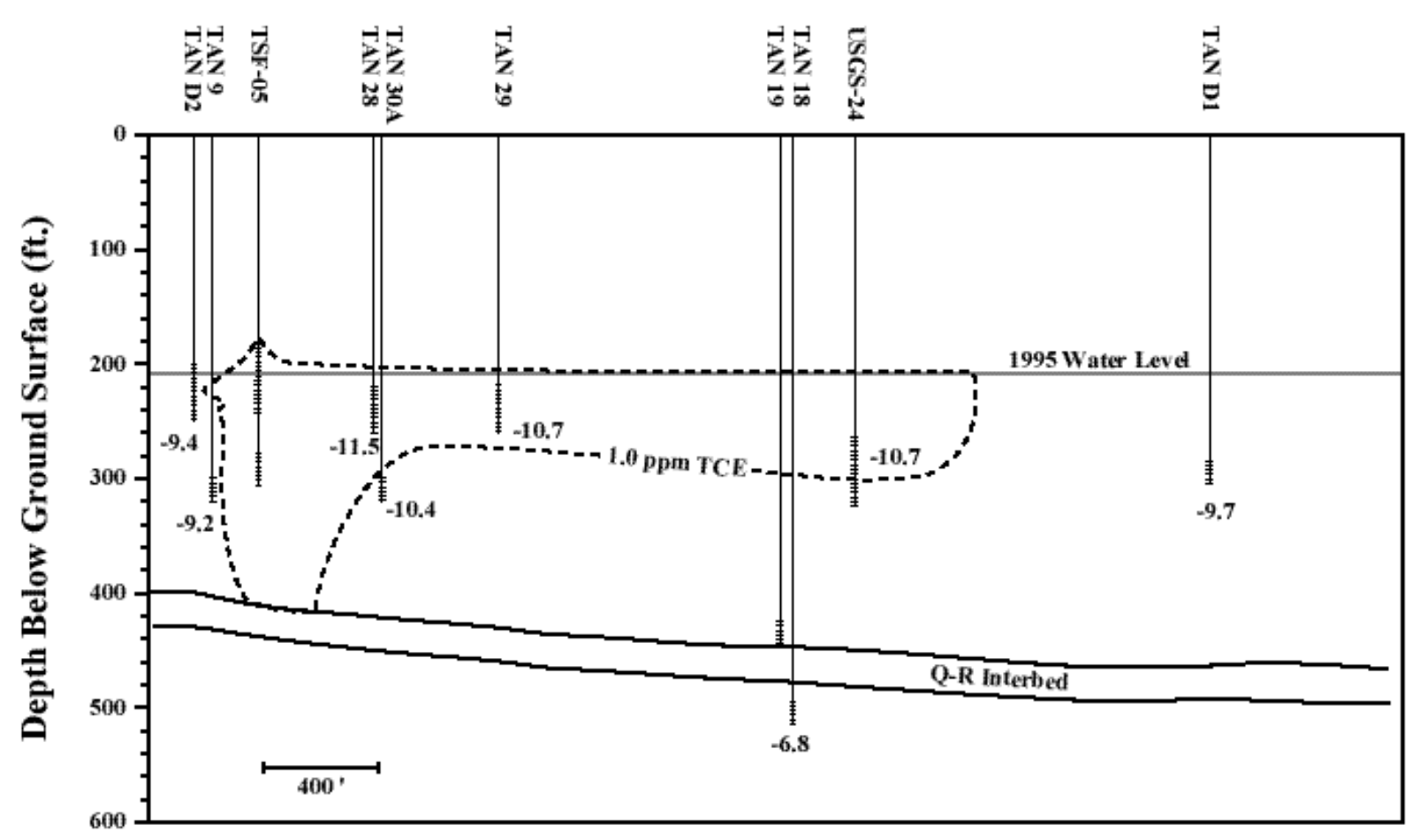

Figure 6. Longitudinal cross section of the TAN plume with the locations of monitoring wells and the $\delta^{13} \mathrm{C}$ values of DIC in the groundwater (the cross-hatched sections of the wells represent the screened intervals). Also plotted are the locations of the $1 \mathrm{ppm}$ TCE contour and the Q-R interbed (the impermeable horizon at the base of the upper, unconfined aquifer).

related to mixing of groundwater during injection) the concentration of TCE drops as the concentration of cis-1,2-DCE increases. The $\delta^{13} \mathrm{C}$ values of the cis-1,2-DCE is initially only about $2 \%$ less than the $\delta^{13} \mathrm{C}$ values of the TCE, reflecting the relatively small shift in carbon isotope ratios observed for this step in the dechlorination process. After about 120 days, vinyl chloride was detected in the samples. The $\delta^{13} \mathrm{C}$ value of the vinyl chloride was $\sim 25 \%$ o less than the $\delta^{13} \mathrm{C}$ value of the cis-1,2-DCE. As the cis-1,2DCE concentrations decreased, its $\delta^{13} \mathrm{C}$ value increased along with the $\delta^{13} \mathrm{C}$ value of the vinyl chloride. The changes in the isotopic compositions of the cis-1,2-DCE and the vinyl chloride confirmed that biologic dechlorination was the primary mechanism responsible for the decrease in the concentrations of cis-1,2-DCE despite only moderate increases in the concentrations of vinyl chloride. A similar argument can be made for the degradation of vinyl chloride to ethene, indicating that complete reductive dechlorination of the TCE was occurring. Similar trends were observed in the other monitoring wells.

These results clearly indicate the use of isotopic monitoring of reductive dechlorination. Although vinyl chloride and ethene were detected in the monitoring wells, their concentrations was relatively low compared to the concentrations of TCE and cis-1,2-DCE. Despite this, the $\delta^{13} \mathrm{C}$ data clearly indicated that complete reductive dechlorination was occurring and the lower concentrations of vinyl chloride and ethene were due to other processes such as volatilization and dispersion. 


\section{TAN 26}
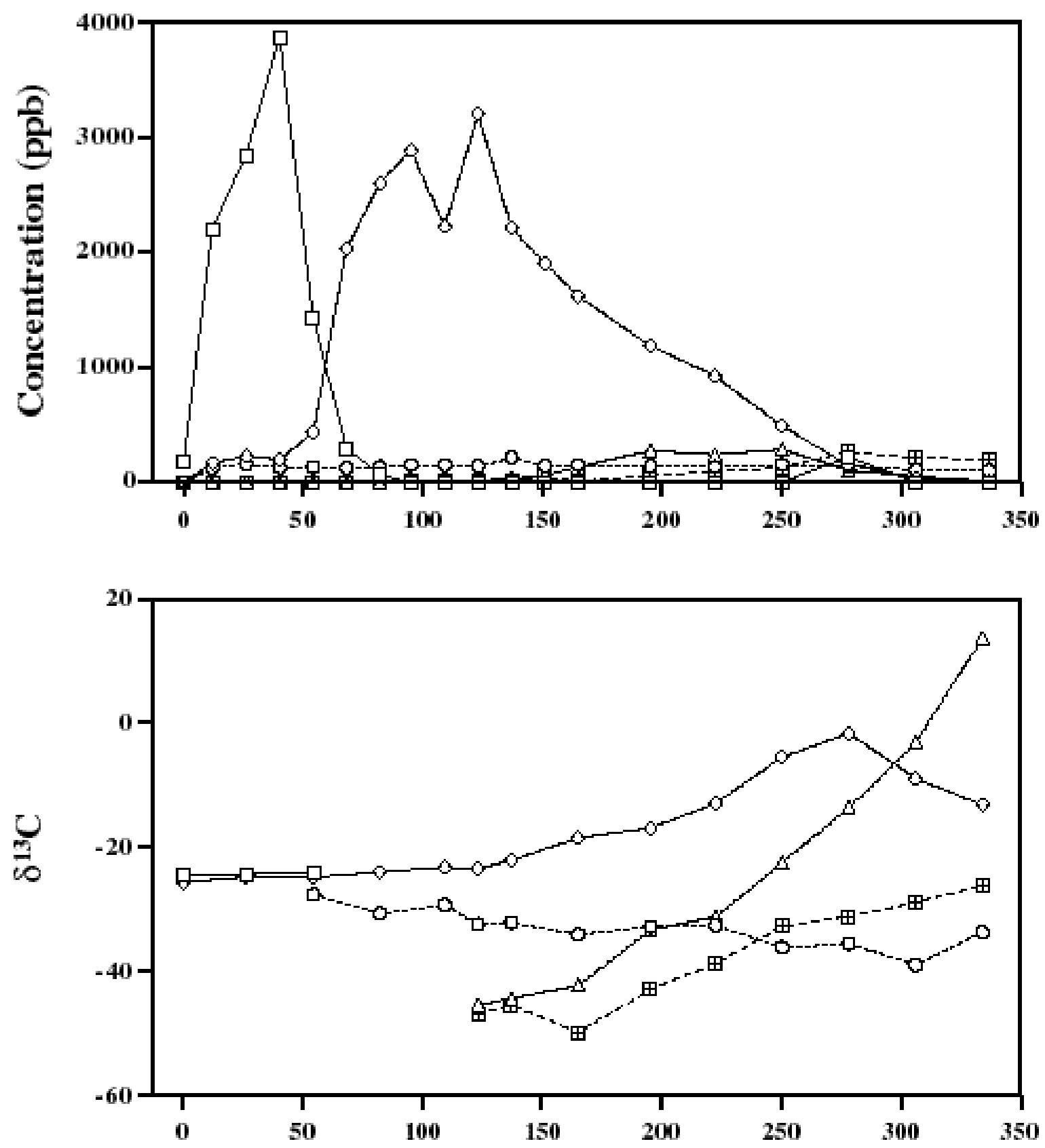

\section{Days}

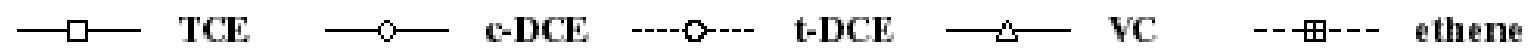

Figure 7. Concentration and carbon isotope data for chlorinated ethenes in samples collected from monitoring well TAN-26 during the enhanced bioremediation experiment. 


\section{The Radioactive Waste Management Complex (RWMC)}

\section{Research Objectives}

The RWMC is located in the southeast area of the INEEL. The geology of the site consists of a series of basalt flows separated by thin sedimentary interbeds. The depth to groundwater is approximately $150 \mathrm{~m}$; although perched water horizons do exist above some of the interbeds. Radioactive waste resulting from Department of Energy activities is buried at the site. The waste is contained in drums buried in shallow pits (approximately $1.5 \mathrm{~m}$ deep). In addition to the radionuclides, the waste drums also contain significant amounts of chlorinated solvents mixed with lubricating oils. Leakage from the drums has resulted in a plume of vapor phase contaminants in the vadose zone.

A vapor extraction system is currently being used to remediate the solvent plume at the RWMC. This system consists of three treatment units that pump vapor from extraction wells. The vapor is then treated and released to the atmosphere. The effectiveness of this system is not well understood. The contaminant levels in the extracted vapors drop to low levels when the extraction units are in operation, but rebound quickly when the units are shut down. At the current rates of contaminant removal, estimates of the time necessary to meet the regulatory goals range from 100 to 200 years of operation.

In situ bioremediation of the wastes to remove the contaminants and/or control their spread represents an attractive alternative to vapor extraction. There is some evidence that natural biodegradation of the contaminants is already occurring at the RWMC. In addition to the chlorinated solvents that were buried at the site (primarily carbon tetrachloride, perchloroethene, trichloroethene and trichloroethane), the vapor plume also contains several other chlorinated compounds (e.g., chloroform, dichloroethene) that are byproducts of bacterial degradation of the primary contaminants. The main objective of our work at the RWMC was to use isotopic measurements to assess the potential for bioremediation of the organic contaminants at the site.

Approach. One of the primary products of aerobic microbial metabolism of organic compounds is $\mathrm{CO}_{2}$. Increased $\mathrm{CO}_{2}$ concentrations in the vicinity of organic contaminants can indicate that biodegradation of the contaminants is occurring. There are, however, other potential sources for the $\mathrm{CO}_{2}$ (e.g., plant root respiration, biodegradation of natural soil organic matter, dissolution of soil carbonate minerals). To further constrain the origin of subsurface $\mathrm{CO}_{2}$, the stable carbon isotope ratio $\left(\delta^{13} \mathrm{C}\right.$ value $)$ of the $\mathrm{CO}_{2}$ can be analyzed. The $\delta^{13} \mathrm{C}$ ratios of hydrocarbon compounds are generally low relative to most other sources of carbon. Therefore, microbial metabolism of compounds manufactured from hydrocarbons can produce soil gas $\mathrm{CO}_{2}$ with relatively low $\delta{ }^{13} \mathrm{C}$ values where significant degradation of hydrocarbons is occurring. Several field studies of aerobic hydrocarbon bioremediation have noted this effect (Suchomel et al., 1990; Ostendorf and Kampbell, 1991; Aggarwal and Hinchee, 1991).

However, $\delta^{13} \mathrm{C}$ analyses alone can result in inconclusive findings. At many sites there is significant overlap between the stable carbon isotope ratios of the contaminants and of natural organic matter. In addition, certain microbial metabolic processes (e.g., methanogenesis, methane oxidation) can cause large shifts between the stable carbon isotope ratios of the substrates and the products that may lead to ambiguous results. One method of resolving the ambiguities associated with stable carbon isotope measurements is to measure the ${ }^{14} \mathrm{C}$ content of the metabolic byproducts (Conrad et al., 1997). The ${ }^{14} \mathrm{C}$ content of natural organic matter in near surface environments is usually at or near modern atmospheric levels, whereas fossil fuels have no measurable ${ }^{14} \mathrm{C}$. Further, at the level of precision that radiocarbon measurements can be made, the effects of isotopic fractionation are insignificant.

\section{Methods and Results}


To determine the nature and extent of natural biodegradation of organic contaminants at the RWMC, the compositions and $\delta^{13} \mathrm{C}$ values of $\mathrm{CO}_{2}$ in gas samples collected over a two-year period (October, 1996 through November, 1998) from monitoring wells in and around the RWMC were analyzed. In addition, the ${ }^{14} \mathrm{C}$ contents of a subset of the samples were also analyzed. The samples were collected in 1- or 3-liter Tedlar ${ }^{\circledR}$ bags from selected vapor ports in the monitoring wells. The concentrations of $\mathrm{N}_{2}, \mathrm{O}_{2}$ and $\mathrm{CO}_{2}$ in the samples were analyzed by gas chromatograph. These analyses are accurate to $\pm 0.1 \%$. Samples containing low concentrations of $\mathrm{CO}_{2}(<0.2 \%)$ were analyzed using an infrared gas analyzer and are accurate to within $\pm 1 \%$ of the stated values. The $\delta^{13} \mathrm{C}$ and ${ }^{14} \mathrm{C}$ analyses were performed using the techniques outlined in Conrad et al. (1997).

The ranges of $\mathrm{CO}_{2}$ concentrations in samples collected from background monitoring wells are plotted versus depth in Figure 8. The data were highly variable, but generally decreased with depth from approximately $0.3 \%$ at $5 \mathrm{~m}$ to less than $0.1 \%$ below $100 \mathrm{~m}$.

The concentrations of $\mathrm{CO}_{2}$ in the sampling ports from within the SDA were also highly variable. The reason for this variability is not clear. There is some hint that it is related to the operation schedule of the units, but there is no clear correlation. There is also no obvious correlation with seasonal changes.

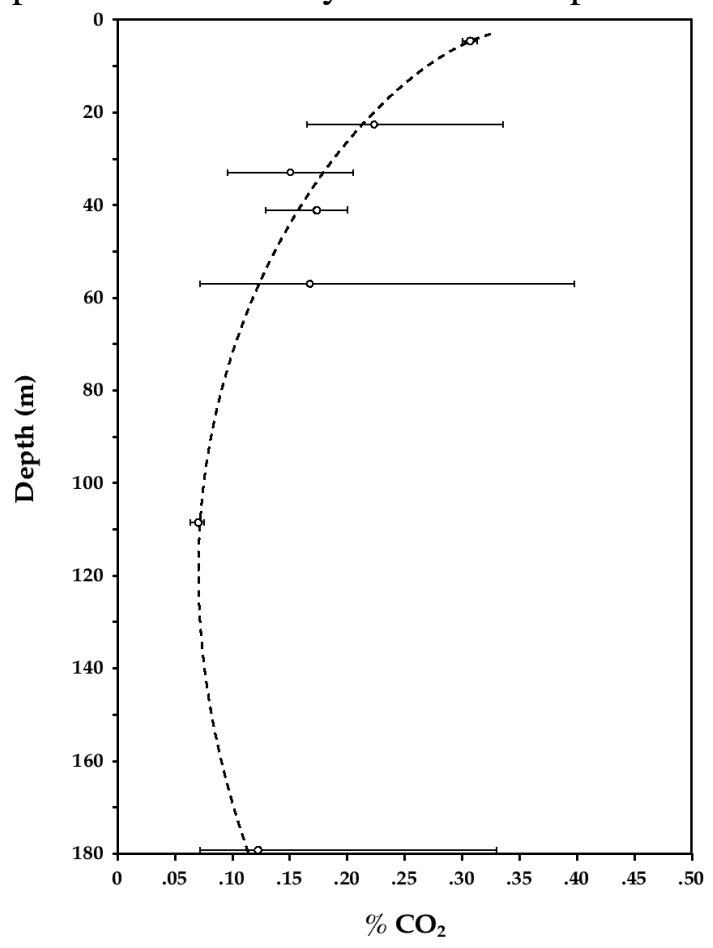

Figure 1. Plot of $\mathrm{CO}_{2}$ concentrations vs. depth in background wells from the RWMC area. Open circles represent average values for all samples taken from a specific sampling port and brackets represent the range of concentrations measured.

Despite the variability, the $\mathrm{CO}_{2}$ concentrations in samples collected from the northern half of the Subsurface Disposal Area (SDA) of the RWMC were clearly elevated above background. Figure 9 contains contour maps of $\mathrm{CO}_{2}$ concentrations for 3 depth intervals at the site. In the shallowest interval (10 to $25 \mathrm{~m}$ ), the concentrations of $\mathrm{CO}_{2}$ averaged greater than $0.7 \%$ in the area to the north of Pit $4 / 6$. In the deeper intervals ( 25 to $40 \mathrm{~m}$ and 40 to $70 \mathrm{~m}$ ), the $\mathrm{CO}_{2}$ concentrations were lower, but were still significantly higher than background levels. In other areas of the SDA, the $\mathrm{CO}_{2}$ concentrations are much closer to background values.

The $\delta^{13} \mathrm{C}$ values of the $\mathrm{CO}_{2}$ in samples from the high- $\mathrm{CO}_{2}$ area were also lower. In background samples, the $\delta^{13} \mathrm{C}$ values of the $\mathrm{CO}_{2}$ ranged from -7\%o (the isotopic composition of atmospheric $\mathrm{CO}_{2}$ ) to $-21 \%$ and averaged $-18 \%$. The $\delta^{13} \mathrm{C}$ values of $\mathrm{CO}_{2}$ in the wells from the area of elevated $\mathrm{CO}_{2}$ ranged from $-9 \%$ o to $-24 \%$ and averaged $-20 \%$. The difference between the $\delta^{13} \mathrm{C}$ values of the background and elevated $\mathrm{CO}_{2}$ samples is not great, but is consistent with production from a low $\delta^{13} \mathrm{C}$ source such as the organic contaminants. This relationship is further demonstrated by Figure 10, which is a plot of the inverse $\mathrm{CO}_{2}$ concentration versus the $\delta^{13} \mathrm{C}$ values of the $\mathrm{CO}_{2}$. Allowing for carbon isotopic fractionation due of diffusion $\left(\sim-4.4 \%\right.$ ), this data suggests a source for the $\mathrm{CO}_{2}$ with a $\delta^{13} \mathrm{C}$ value of between -24 and $-29 \%$. This is a typical range of carbon isotope values for petroleum hydrocarbons. 
In addition to the stable carbon isotope ratios of the samples, the ${ }^{14} \mathrm{C}$ contents of a limited number of $\mathrm{CO}_{2}$ samples were also analyzed. Several samples from the eastern half of the SDA contained high levels of ${ }^{14} \mathrm{C}$ (greater than 5 times the concentration in atmospheric $\mathrm{CO}_{2}$ ). These high values are believed to have been derived from reactor shield blocks buried in the southeast corner of the SDA. Soil gas $\mathrm{CO}_{2}$ in the vicinity of these blocks contains up to 4000 times background levels of ${ }^{14} \mathrm{C}$. Some of the $\mathrm{CO}_{2}$ samples from background wells VVE-6 and M6S (located to $\sim 1 \mathrm{~km}$ to the southeast of the SDA) also had elevated ${ }^{14} \mathrm{C}$ contents (up to 5 times modern levels) suggesting that there has been some vapor transport to this area. There were, however, three samples of $\mathrm{CO}_{2}$ taken from elevated $\mathrm{CO}_{2}$ wells in the northwest section of the SDA that do not appear to have been affected by the radiocarbon buried in the SDA. These samples had ${ }^{14} \mathrm{C}$ levels between 0.00 and 0.13 times modern. These low ${ }^{14} \mathrm{C}$ levels are consistent with being produced from fossil hydrocarbons. It is also possible that they could be produced from dissolution of "old" carbonate minerals in the subsurface, but their $\delta^{13} \mathrm{C}$ values are lower than would be expected (averaging -19.4\%o) if this were the case. No measurements have been made of calcite from the RWMC site, but calcite from the TAN site has $\delta^{13} \mathrm{C}$ values ranging from -3 to $-7 \%$ (Tobin et al., 1997). Assuming that calcite at the RWMC has a similar range, the $\delta^{13} \mathrm{C}$ value of $\mathrm{CO}_{2}$ produced from dissolution of the calcite should be much higher than $-19.4 \%$.

Significance of Findings. The $\mathrm{CO}_{2}$ concentrations in the subsurface in the northern section of the RWMC are elevated by 3- to 5-fold relative to background. The low ${ }^{14} \mathrm{C}$ concentrations in $\mathrm{CO}_{2}$ from several of these samples also indicate that it was derived from degradation of contaminants produced from fossil fuels. It is not clear, however, whether this $\mathrm{CO}_{2}$ is produced from degradation of the 

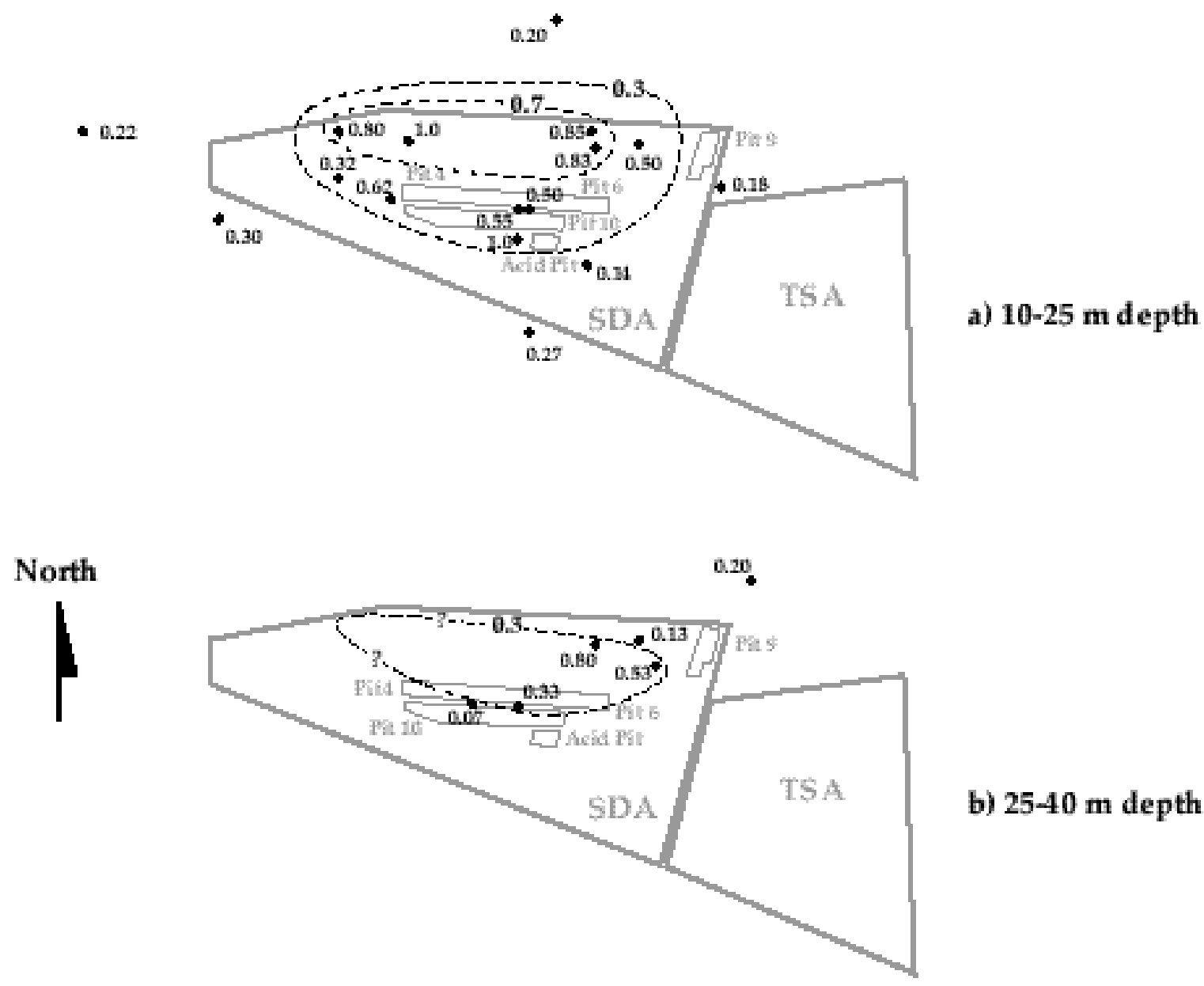

b) $25-40 \mathrm{~m}$ depth
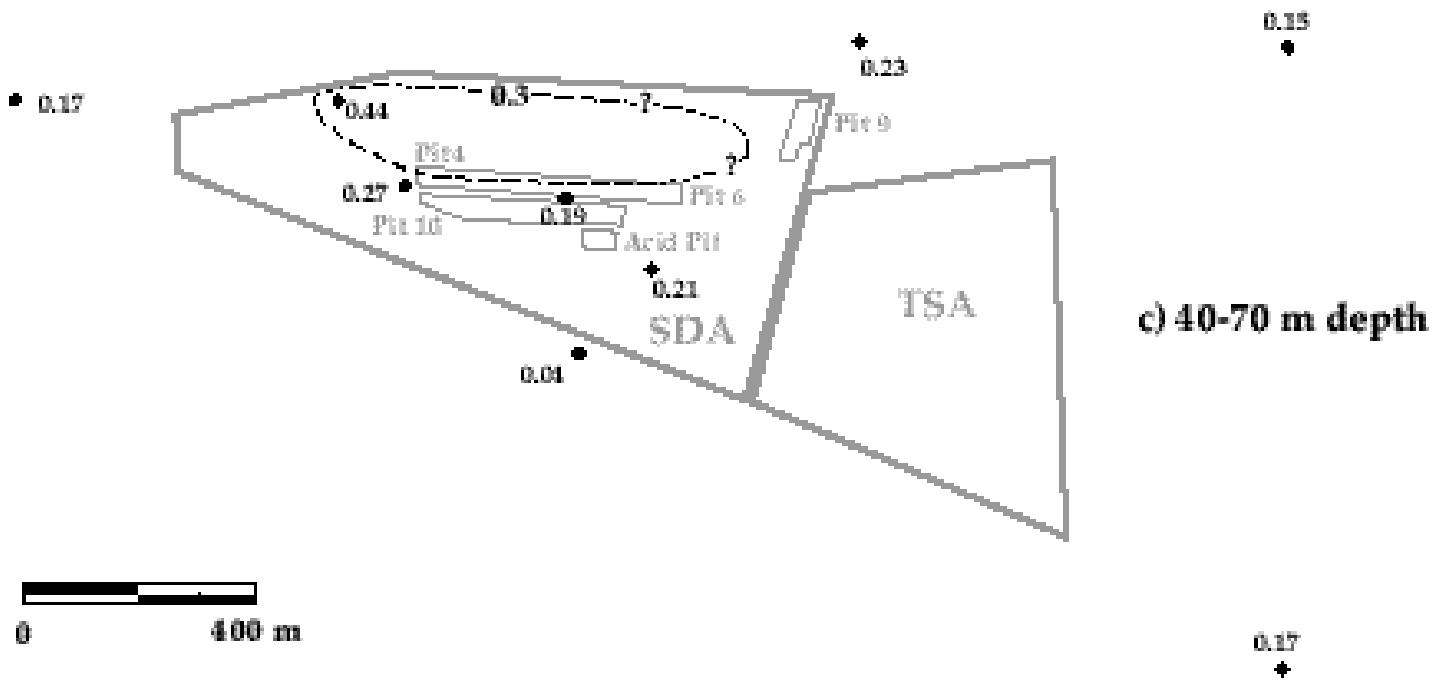

\section{*.4. Sampling point with average $\% \mathrm{CO}_{2}$}

Figure 9. $\mathrm{CO}_{2}$ concentrations $(\%)$ in vapor samples collected from different depth intervals in and around the RWMC site. Background wells are located in the lower right and the far left. 


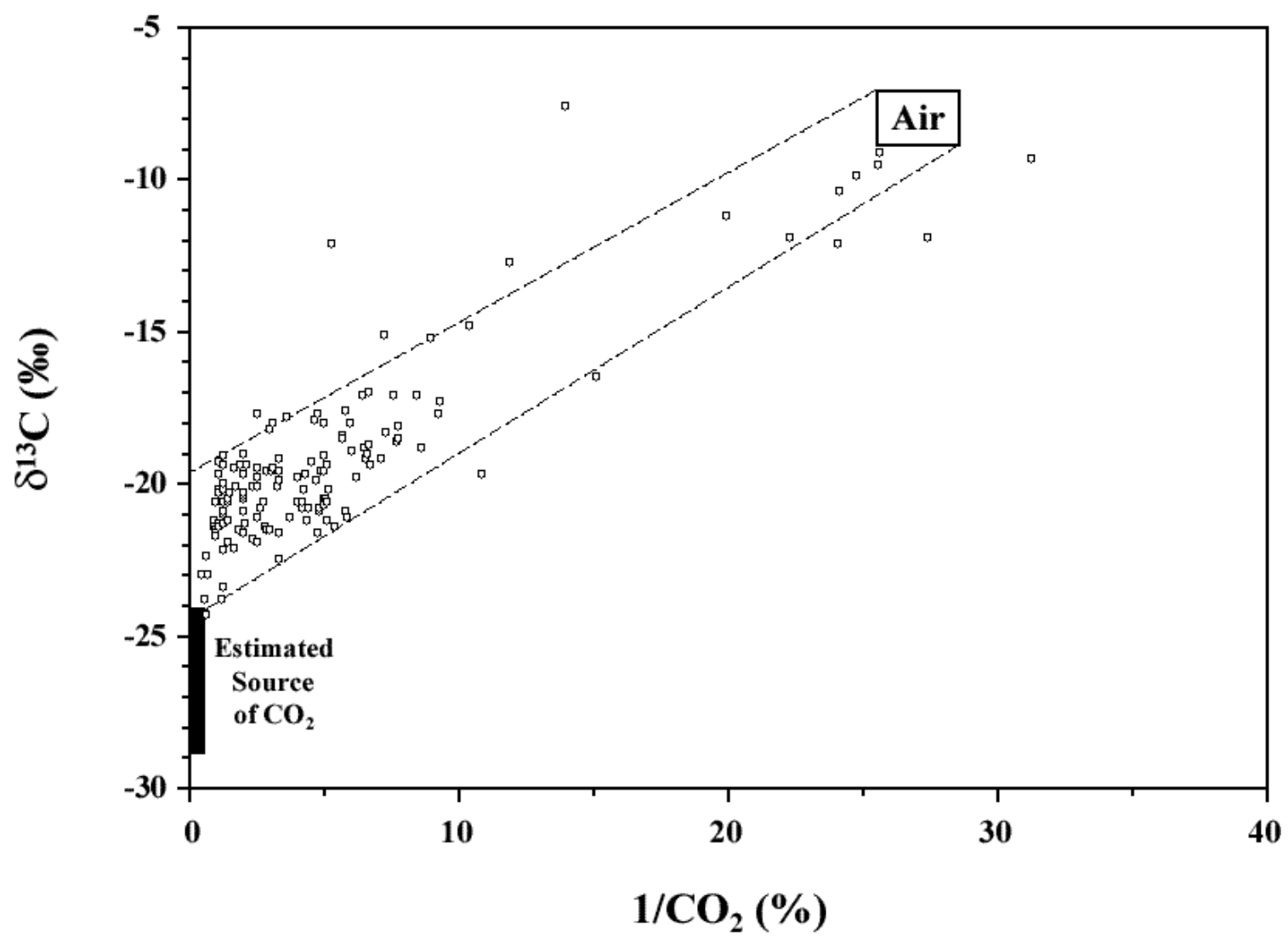

Figure 10. Inverse concentrations of $\mathrm{CO}_{2}$ in vapor samples from between 10 and $70 \mathrm{~m}$ depth from the RWMC site. Allowing for a shift of $4.4 \%$ o for diffusive fractionation, this data suggests that the source for the increased $\mathrm{CO}_{2}$ in the vicinity of the disposal pits of have $\delta^{13} \mathrm{C}$ values of between -24 and $-29 \%$.

chlorinated solvents, the lubricating oils, or some combination of both (or some other, undetermined organic waste buried at the site). To determine the nature and extent of biodegradation of the chlorinated solvents would require direct measurements of the $\delta^{13} \mathrm{C}$ values of the contaminants and there potential byproducts (see the section on "Monitoring Enhanced Bioremediation of TCE" in the discussion of the results from the TAN site).

\section{Hanford Groundwater}

\section{Research Objectives}

In the last year of the grant, we were able to develop a collaborative arrangement with scientists at PNNL to measure $\mathrm{Sr}, \mathrm{O}, \mathrm{C}$, and $\mathrm{H}$ isotopes in groundwater from the Hanford site in south central Washington. Substantial progress was made in analyzing groundwater samples during the last 6 months of the grant period, but there was too little time to complete the measurements and data analysis.

The objective of adding Hanford to the field study program is that it is probably the best site in the DOE complex to allow us to understand the behavior of the natural isotopic tracers. A very large amount of water containing radioactive and other contaminants was discharged to the vadose zone at Hanford starting in the 1940's and continuing until the 1980's. Groundwater plumes of tritium, 
technetium, iodine-129, nitrate and other species confirm that much of the released water reached the water table. In some areas, sufficient water was added to raise the water table by more than 20 meters, and in other areas the direction of groundwater flow was changed as a result of the releases.

Transport of radionuclides and other contaminants through the vadose zone is a complicated hydro-geochemical problem. Due to inhomogeneous and transient flow, variable recharge, chemical interactions between waste fluids, soils, and rocks, coupled processes, and intrinsic limitations to the characterization of the hydrologic medium, it is difficult to make reliable predictions of contaminant mobility. The resultant uncertainties impact the EM mission because they call into question the basis for remediation and monitoring decisions affecting a large number of contaminated sites in the DOE complex.

A key objective is to obtain data that can be used to develop conceptual models of the migration of radionuclides through the unsaturated zone and into groundwater. Ultimately, these conceptual models are turned into computational models, and the computational models become the basis for making decisions about how to (or whether to) remediate and monitor contaminated sites. The models also form the basis for making assessments of the environmental impacts of the contamination on short and long time scales, and for assessing how useful a particular remediation strategy will be. Specifically, we wish to determine whether:

1. The isotopic compositions of $\mathrm{O}, \mathrm{H}, \mathrm{C}$, and $\mathrm{Sr}$ in near-field groundwater samples can be used to evaluate the presence of- and sources of waste fluids, and therefore evaluate the fluid transport independent of the contaminants.

2. The isotopic compositions of $\mathrm{O}, \mathrm{H}, \mathrm{C}, \mathrm{Sr}$, and $\mathrm{N}$, in near-field groundwater samples can be used to determine whether chemical processes (dissolution-precipitation, evaporation, microbial processes) significantly perturb transport of radionuclides.

There are three main reasons why the isotopic tracers $\mathrm{Sr}, \mathrm{O}, \mathrm{C}$, and $\mathrm{H}$ should be sensitive tracers of past Hanford activities.

1. The water used for industrial activities and for waste disposal at Hanford was exclusively derived from the Columbia River. The Sr isotopic ratio of Columbia River water is distinct from the ambient groundwater of the Hanford site. The ambient groundwater emanates from Columbia River basalt host rocks on the western and southern margins of the site and therefore has a low value of ${ }^{87} \mathrm{Sr} /{ }^{86} \mathrm{Sr}$. Columbia River water has a much higher value of ${ }^{87} \mathrm{Sr} /{ }^{86} \mathrm{Sr}$. Prior to beginning the analyses we did not know how different the Columbia River water was, but now we know that there is a very large isotopic contrast and therefore that $\mathrm{Sr}$ is a sensitive tracer of water introduced to the environment by Hanford activities.

2. Some of the water disposed to the vadose zone was strongly evaporated before release. Evaporation imparts to the residual water an identifiable isotopic signature in terms of the relative values of $\delta^{18} \mathrm{O}$ and $\delta \mathrm{D}$. The oxygen and hydrogen isotopic character of strongly evaporated water may be useful for identifying the source of specific contaminants in the vadose zone. Strongly evaporated water is identified primarily with tank waste, as opposed to water disposed to cribs, trenches and retention basins.

3. Columbia River water also has a carbon isotopic signature that differs from the ambient groundwater of the Hanford site. It now appears that this natural tracer can be used like Sr to track the additions of river water to the site groundwater budget. However, carbon isotopes may also be sensitive to chemical reactions that occur in the vadose zone, such as dissolution of carbonate (caliche) and biodegradation of hydrocarbons. 
4. Soil carbonate may have a $\mathrm{Sr}, \mathrm{C}$, and $\mathrm{O}$ isotopic signature that is distinguishable from Columbia River water and from normal groundwater. The involvement of dissolution ( \pm precipitation) reactions involving soil carbonate may be detectable.

\section{Methods and Results}

Over 200 samples of groundwater were collected during 1999 for isotopic analysis as part of the normally scheduled sampling for the Hanford Groundwater Monitoring Program. We have measured most of these samples for ${ }^{87} \mathrm{Sr} /{ }^{86} \mathrm{Sr}$, and a smaller number have been measured for oxygen, hydrogen and carbon isotopes. There has been insufficient time and funds to complete measurements and data analysis, but some important preliminary observations have been made.

1. The Sr isotopic composition of Hanford groundwater is highly variable. The influence of waste fluids on the groundwater is easily detectable and widespread. There is extreme heterogeneity on many scales, mostly resulting from waste fluid introduction. The $\mathrm{Sr}$ isotopic composition of groundwater does not change rapidly as water flows from one geologic unit to another, indicating that $\mathrm{Sr}$ isotopes can be used to source waters.

2. Evidence of evaporation effects is present in the oxygen isotopic composition of some Hanford groundwater.

3. Carbon isotope values of normal groundwater are distinct from that of Columbia River water.

4. Large shifts of the carbon isotope values of DIC are apparent in areas with significant organic contamination.

The results so far indicate that the isotope systems chosen for study will provide essential new information about the hydrology and hydrochemistry of the Hanford site. 


\section{Relevance, Impact and Technology Transfer}

\section{A. How does this new scientific knowledge focus on critical DOE environmental management problems?}

Some of the most difficult issues at most contaminated sites include determining the extent of contamination, identifying transport pathways, and determining the impact of natural, in situ processes on the contaminants (either good or bad). Since many of the biggest environmental problems facing DOE are located in the subsurface, this is especially true. The isotopic methods we have been developing and refining with this project provide additional, complementary techniques for answering these characterization and monitoring questions.

\section{B. How will the new scientific knowledge that is generated by this project improve technologies} and cleanup approaches to significantly reduce future costs, schedules, and risks and meet DOE compliance requirements?

These isotopic techniques can be used for a variety of purposes:

1. Natural isotopic tracers can often be used instead of expensive infiltration tests to determine critical factors such as infiltration pathways, flow rates, and groundwater mixing (e.g., the work on the TAN regional hydrology, the use of strontium isotopes at Hanford). This information is invaluable for designing the most efficient, cost effective remediation program.

2. Isotopic measurements can be used to quantify the degree of intrinsic degradation of contaminants occurring at a site (e.g., the TAN plume, the RWMC site). This evidence can be used to argue the extent to which natural processes are adequate for limiting the spread of the contaminants.

3. The carbon isotopic compositions of chlorinated solvents can be used to determine the nature and extent of degradation of those compounds in the subsurface (e.g., the engineered bioremediation experiment at the TAN site). These processes have been notoriously difficult to monitor, often leading to misinterpretation of results which can lead to costly problems and/or difficulty in convincing regulators and stake-holders that the problems are being adequately addressed.

\section{To what extent does the new scientific knowledge bridge the gap between broad fundamental research that has wide-ranging applications and the timeliness to meet needs-driven applied technology development?}

Our studies of monitoring natural and engineered bioremediation of chlorinated solvents are some of the first field results that demonstrate the efficacy of these process. There have been a number of laboratory studies, but it has been difficult to translate these results to field settings. In addition, the use of natural isotopic tracers has great potential for providing the framework to address some of the more intractable problems associated with contaminant transport in the vadose zone (e.g., identifying pathways, determining the extent of retardation contaminants).

D. What is the project's impact on individuals, laboratories, departments, and institutions? Will results be used? If so, how will they be used, by whom, and when?

The results of these studies have led to a number of additional projects including:

1. Analyses of groundwater samples to evaluate the potential for natural attenuation of chlorinated contaminants at the Lawrence Berkeley National Laboratory (LBNL). This project was funded by the LBNL Site Restoration Program and was just recently finished. 
2. Monitoring of processes accompanying engineered remediation of chloroethenes at Site 300 at the Lawrence Livermore National Laboratory. This project just began and is part of a larger study of biologic processes occurring at this site.

3. Two projects designed to study infiltration pathways in the vadose zone at the Hanford site (isotopic measurements of core samples and the use of isotopically-enriched tracers in conjunction with field infiltration tests). These projects started during this fiscal year and are funded by the Hanford Site Restoration Program.

4. A project to study infiltration and transport of waste waters and radionuclides at the Idaho Nuclear Technology and Engineering Center (INTEC) previously known as the Idaho Chemical Processing Plant. This project is currently slated for funding from the Subsurface Contamination Focus Area program of EM50 beginning in FY01.

In addition, there are several other projects that are currently under consideration for funding.

\section{E. Are larger scale trials warranted? What difference has the project made? Now that the project} is complete, what new capacity, equipment or expertise has been developed?

Larger-scale are certainly warranted. The additional projects that have started as a result of this work (see above) confirm this. For some aspects of the project (specifically the Hanford work) we have applied for follow-up funding to further refine the techniques and develop new isotopic methods of tracking groundwater movement.

The exact impact of this project on specific issues is difficult to quantify (especially in monetary terms). The information that was generated has certainly been useful in helping guide decisions on effective remediation practices (e.g., the enhanced bioremediation experiment at the TAN site).

The biggest result of the project is new expertise in using and interpreting isotopic data for environmental remediation. The use of isotopic methods for tracking bioremediation is a relatively new area and the data from this project are some of the first field data demonstrating its usage. Similarly, the use of isotopic measurements of elements such as strontium to track infiltration and movement of water is a relatively new concept and the results of this study certainly demonstrate how that can be done. Otherwise, a new analytical technique for measuring low concentrations of organic compounds in groundwater (manuscript in prep) also came out of this project.

\section{F. How have the scientific capabilities of collaborating scientists been improved?}

The collaborating scientists at both INEEL and Hanford have learned a lot about the potential use of isotopic measurement to address scientific issues related to environmental remediation. In the case of INEEL, several new projects have been started as a result of suggestions by the scientists there.

\section{G. How has this research advanced our understanding in the area?}

The results of this project have contributed to basic scientific information about processes such as subsurface biological activity, biodegradation of contaminants and infiltration of surface waters. They have also provided a framework for interpreting specific processes at the study sites.

H. What additional scientific or other hurdles must be overcome before the results of this project can be successfully applied to DOE Environmental Management problems?

From a scientific standpoint, these techniques have to be refined so that they can be used to quantify certain processes. As they stand now, they only give qualitative or semi-quantitative estimates of 
what is happening. Other than that, the main obstacle to wider acceptance of these techniques is a general lack of knowledge about isotopic measurements. This will undoubtedly come as more field data and examples of applications become available.

\section{Project Productivity}

The general goal of the original proposal was to "... to evaluate and refine the use of isotopic measurements of groundwater and vadose zone gas to monitor subsurface remediation." In this regard, the project was a substantial success. The specific scope of the project was shifted somewhat for a number of reasons including unforeseen regulatory restrictions, unanticipated results and advances in the scientific techniques.

At the TAN site, we did not receive any samples until the end of the first year of the project because of regulatory problems. We were able to complete the general survey of the groundwater that was originally proposed and some follow-up sampling that fell under the scheduled monitoring plan, but were not allowed to take any additional samples. Instead, we did an extensive regional survey of the groundwater to define the different components discovered in the plume. In addition, we expanded the scope of the project to include the isotopic study of the enhanced bioremediation experiment.

For the work at the RWMC, we were able to collect gas samples over a two -year period as proposed. However, regulatory issues and time delays due to safety shut-downs prevented us from doing the tracer experiments that were planned.

The most significant change from the proposed scope was the addition of the groundwater sampling at the Hanford site. Many of the most significant environmental issues facing the DOE are at Hanford. In addition, the complex nature of many of the Hanford problems are ideal for study using natural isotopic tracers. When the opportunity to expand our research to Hanford came up, we decided to take advantage of it.

\section{Personnel Supported}

\section{At LBNL:}

1. Donald DePaolo (Faculty)

2. Mark Conrad (Geological Scientist)

3. B. Mack Kennedy (Staff Geological Scientist)

4. Allen Dodson (Postdoctoral Fellow)

5. Simon Davis (Postdoctoral Fellow)

6. Donald Song (Graduate Student)

At INEEL:

1. Eric Miller (Hydrogeologist)

2. Erick Neher (Hydrogeologist)

3. Thomas Wood (Hydrogeologist)

\section{Publications}

\section{A. Peer-reviewed Journals and Books}


Conrad, M.E., and B. Faybishenko, in press, Isotopic tracers of flow and transport through the vadose zone: In eds., Looney, B., and R. Falta, Vadose Zone Technology and Science Solutions, Batelle Press, Columbus, $\mathrm{OH}$.

Brief description: This section of a book discusses applications of isotopic measurements to water movement through the vadose zone and is illustrated with an example from the work done for this project at the TAN site.

Geller, J.T., H.-Y. Holman, G. Su, T-S. Liou, M.E. Conrad, K. Pruess, and J.C. Hunter-Cevera, 2000, Flow dynamics and potential for biodegradation of organic contaminants in fractured rock vadose zone: J. Contaminant Hydrology 33, 63-90.

Brief description: This paper includes a discussion of the isotopic evidence collected by this study for biodegradation of the organic contaminants in the vadose zone at the RWMC.

\section{B. Proceedings, Abstracts}

Conrad, M.E., D.J. DePaolo, and P. Evan Dresel, 2000, Natural isotopic tracers of infiltration through the vadose zone at the Hanford site, Washington: EOS, Trans., Am. Geophys. Union 81, no. 19, S230.

Conrad, M.E., D.J. DePaolo, D.L. Song, and E. Neher, 1999, Isotopic evidence for groundwater flow and biodegradation of organic solvents at the Test Area North site, Idaho National Engineering and Environmental Laboratory: In Ninth Annual V.M. Goldschmidt Conference, pp. 58-59, LPI Contribution No. 971, Lunar and Planetary Institute, Houston.

Song, D.L., L. Alvarez-Cohen, M.E. Conrad, and K. Sorenson, 1999, Monitoring of enhanced in-situ bioremediation of trichloroethylene using stable carbon isotopes: Program and Abstracts for the 4th International Symposium on Subsurface Microbiology, Vail, Colorado.

Conrad, M.E., D.J. DePaolo, B.M. Kennedy, and E.C. Miller, 1997, Carbon isotope evidence for degradation of mixed contaminants in the vadose zone: Geol. Soc. Am., Abst. with Prog. 26, no. 6, A186.

\section{Interactions}

\section{A. Participation/presentations at meetings, workshops, conferences, seminars, etc.}

Fractured Rock Science Meeting at the Idaho National Engineering and Environment Laboratory during March, 1997 (presentation by Conrad).

Special Session on "Isotopic Tools for Detection of the Origin and/or Fate of Environmental Contaminants" at the 1997 Geological Society of America Annual Meeting in Salt Lake City, Utah (presentation by Conrad).

1998 EMSP National Workshop in Chicago, Illinois (DePaolo).

Fractured Rock Science Meeting at the Idaho National Engineering and Environment Laboratory during August, 1998 (Conrad, Davis).

Special Session on "Isotopic Tracers of Human Influence on the Environment" at Ninth Annual V.M. Goldschmidt Conference in Cambridge, Massachusetts during August, 1999 (presentation by Conrad). 
4th International Symposium on Subsurface Microbiology in Vail, Colorado during August, 1999 (presentation by Song).

2000 EMSP National Workshop in Atlanta, Georgia (Conrad).

Special Session on "Recent Advances in Using Tracers for Interpreting Hydrogeologic Systems" at the 2000 American Geophysical Union Spring Meeting in Washington, DC (presentation by Conrad).

\section{B. Consultative and advisory functions to other laboratories and agencies}

Hanford committee by Don???

\section{Collaborations}

Numerous collaborations with scientists at both INEEL and Hanford have resulted from this project, some of which have led to future projects (see Future Work section below).

\section{Transitions}

\section{A. Describe cases where knowledge resulting from you effort is used...}

To date, the most direct application of our results has been to the design of the enhanced bioremediation program planned for the TAN site. Some of the new projects that have been started or will be started soon (see below) have built on our earlier results.

\section{Future Work}

At the INEEL, a project to use isotopes to determine the sources of groundwater and contaminants at the INTEC site is scheduled to receive funding from the Subsurface Contamination Focus Area program of EM50 beginning in FY01. In addition, plans are being made to collect and analyze the carbon isotope compositions of chlorinated solvent compounds in the RWMC plume in order to assess the potential for biodegradation of the contaminants.

At Hanford, we have begun two projects designed to study infiltration pathways in the vadose zone. A proposal for continuing EMSP funding to continue the groundwater studies begun with this project has also been submitted.

\section{Literature Cited}

Aggarwal, P.K. and Hinchee, R.E., 1991, Monitoring in situ biodegradation of hydrocarbons using stable carbon isotopes: Environmental Science and Technology 25, 1178-1180.

Conrad, M.E., Daley, P.F., Fischer, M.F., Buchanan, B.B., Leighton, T., and Kashgarian, M., 1997, Combined ${ }^{14} \mathrm{C}$ and $\delta^{13} \mathrm{C}$ monitoring of in situ biodegradation of petroleum hydrocarbons: Environmental Science and Technology 31, 1463-1469.

Craig, H., 1961, Isotopic variations in meteoric waters: Science 133, 1702-1703. 
Hunkeler, D., Aravena, R. and Butler, B.J., 1999, Monitoring microbial dechlorination of tetrachloroethene (PCE) in groundwater using compound-specific stable carbon isotope ratios: Microcosm and field studies: Environmental Science and Technology 33, 2733-2738.

Johnson, T.M., and Depaolo, D.J., 1997a, Rapid exchange effects on isotope ratios in groundwater systems, 1. Development of a transport-dissolution-exchange model: Water Resources Research 33, 187-195.

Johnson, T.M., and Depaolo, D.J., 1997b, Rapid exchange effects on isotope ratios in groundwater systems, 2. Flow investigation using Sr isotope ratios: Water Resources Research 33, 197-205.

Ostendorf, D.W. and Kampbell, D.H. (1991) Biodegradation of hydrocarbon vapors in the unsaturated zone: Water Resources Research 27, 453-462.

Suchomel, K.H., Kreamer, D.K. and Long, A. (1990) Production and transport of carbon dioxide in a contaminated vadose zone: a stable and radioactive carbon isotope study: Environmental Science and Technology 24, 1824-1831.

Tobin, K.J., Onstott, T.C. and Colwell, F., 1997, Establishing background calcite mineralization as a prelude to an in situ bioremediation effort (INEL, Idaho): Geological Society of America, Abst. with Prog. 26, no. 6, A153.

\section{Feedback}

Appendices

\section{Quantities/Packaging}

